Mahdi $\mathcal{E}$ Madlool, 2021

Volume 6 Issue 3, pp. 236-249

Date of Publication: 11 th January 2021

DOI- https://doi.org/10.20319/pijss.2021.63.236249

This paper can be cited as: Mahdi, D. S. E Madlool, J. K. (2021). Impact of Healthcare Knowledge Management on the Strategic Position of Hospitals: An Analytical Study. PEOPLE: International Journal of Social Sciences, 6(3), 236-249.

This work is licensed under the CreativeCommons Attribution-NonCommercial 4.0 International License. To view a copy of this license, visit http://creativecommons.org/licenses/by-nc/4.0/ or send a letter to Creative Commons, PO Box 1866, Mountain View, CA 94042, USA.

\title{
IMPACT OF HEALTHCARE KNOWLEDGE MANAGEMENT ON THE STRATEGIC POSITION OF HOSPITALS: AN ANALYTICAL STUDY
}

\author{
Dalal Salih Mahdi \\ Pharmacy College- Tikrit University, Tikrit, Iraq \\ dalal.salih@tu.edu.iq \\ Jaleel Kadhim Madlool \\ College of Management and Economy, University of Sumer, Najaf, Iraq \\ j.alaardhy@yahoo.com
}

\begin{abstract}
Healthcare knowledge management HKM has attracted extensive attention in the previous years as a strategical partner with the general strategy of organizations. The HKM aims to identify the organization strategic position within the competitive market. The present study tries to answer many questions that formed the study problem including do hospitals and health units depend on the healthcare knowledge storage to perform its strategical tasks and how to run this healthcare knowledge; does the healthcare knowledge transformation represent the main base to attain these especial strategic tasks by identifying its strategic position. A virtual form has been proposed that reflects the interaction relation nature between variables. The virtual form is clarified by the study's main assumption which was tested using data obtained from surveys and other different data collecting methods about different Iraqi hospitals and health units. The study highlighted the significant role of the HKM in hospitals and health units. Also, it was found that the Iraqi hospitals
\end{abstract}


and health units have a growing interest to diagnose its weaknesses to build a strong internal environment. The present study recommends holding training courses continuously to improve the staff's abilities. In addition, the study recommends establishing environmental analysis units to study and evaluate environmental changes.

\section{Keywords}

Healthcare Knowledge Management (HKM), Strategy, Maturity, Strategic Position, Calculated (t) Value, Statistical Analysis

\section{Introduction}

Knowledge management (KM) has become one of the key strategies adopted by various organizations (Baskici, 2017). KM improves organizations performance and enhances their ability to develop in an era in which humanity is witnessing a knowledge revolution. Furthermore, KM is one of the main factors that distinguish organizations in general in the twenty-first century. The healthcare section can advantage of KM through improving the quality of care, reducing cost and medical error, and enhancing organizational learning and organizing knowledge (El Morr and Subercaze, 2010, Almansoori, et al., 2020, Sensuse et al., 2014).

\subsection{Healthcare Knowledge Management (HKM)}

The main objective of Healthcare knowledge management (HKM) is to create value, raise and refine the basic healthcare knowledge of healthcare organizations. The application of the HKM has many dimensions, such as strategy, structural culture, structural operations, management and leadership, technology, requirements, policy, and market opportunities (Hajric, 2018, Yulita and Nasution, 2019).

Preparing a model of mature healthcare knowledge expresses a revolutionary and comprehensive method (Klimko, 2001). This method will improve organization development with time through different levels of maturity towards a final perfect state. (Mark, et. al., 1993) confirmed that maturity is a scale of effectiveness. Maturity represents a clear limit of a specific operation, the reached limit by its administrative, measurement, and control. Maturity does not refer to the possibility of growing ability; it focuses on enrichment and harmony in execution (Mark, et. al., 1993). It is important to point out that the proposed definition in (Mark, et. al., 1993) is closely related to the administrative processes related to planning, organizing, and controlling. Similarly, (Kruger and Johnson, 2010) assumed that most of the maturity models are natural by their selves. The eventual 
goal is to enhance operations and improve business. The capability maturity concept is related to computer software development (Paulk, et. al., 1991). It is used to evaluate the ability to develop computer programs in hospitals and health units. The progress within the levels of the capability maturity model cannot be accomplished quickly by heading directly toward the higher level. In order to demonstrate the merit within the framework of the main processes identified within each level, it is necessary to move or shift between the scale stages or levels by logical sequence.

\subsection{The Strategic Position of Organizations}

The strategic position is related to the competencies influence on organization strategy. Competition is the organization motivation to continuously develop its strategies to keep in track with competitive situations and gain profits by finding and creating enhanced and preserved competitive advantages (Al-Ma'adidi, 2001). The aspects of positive competition based on recognition and respect for others, betting on exerting effort, and negativity indicating the person who chose to be successful in terms of not content without having value. The competition provides the organization with high motivation to create value so that it can survive and grow through improvement and innovation and what distinguishes it from competitors (Najm, 2010).

\subsection{Study Issues}

In the present paper, the impact of the HKM on the strategic position of hospitals and healthcare units was studied. The investigated HKM dimensions are socialization, internalization, and combination. The studied strategic position dimensions are market opportunities, competitors threaten, emerging risks, and basic organizational assumptions. In order to frame the present study problem, the following questions are acknowledged:

- What is the relationship between healthcare knowledge management (HKM) and the strategic position of an organization?

- Does the HKM differ from one organization to another, according to its relation to the size and importance of the strategic position to decide the organization strategic option?

The academic importance of the present study is presented in two aspects. The first aspect is presenting the frames and intellectual treatments related to the main terms of the study: HKM and strategic position. The second aspect is applying theoretical concepts and ideas in the field, i.e., Iraqi organizations.

The present study aims to: 
- Determine the relationship between hospital healthcare knowledge management and the strategic position.

- Diagnose and show the relationship at the level of hospitals and healthcare units

- Determine a method to test the relationship between hospital HKM and the strategic position.

\section{Methodology}

In light of the study problem and its objectives, the study adopts a theoretical model to explain the studied phenomenon. To translate the study problem into procedural variables, the study adopts a model that links the dependent variable (HKM); represented in its dimensions, i.e., market opportunities, competitor threats, competitive risks, and basic regulatory assumptions (Nwokah and Ondukwu, 2009) (Fahey, 2007); with the strategic position, as shown in Figure 1.

Healthcare Knowledge Management
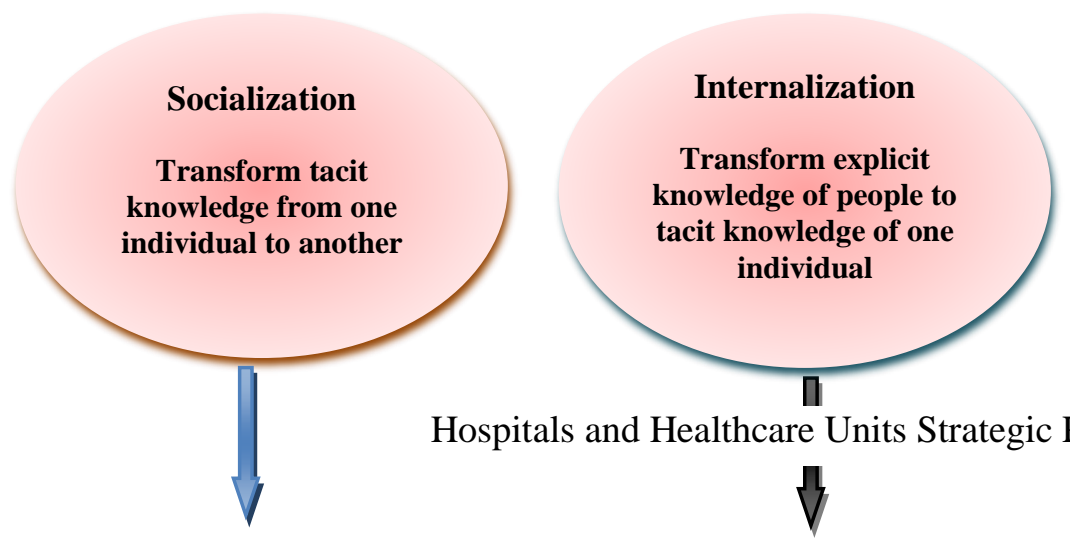

Hospitals and Healthcare Units Strategic Position

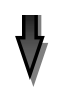

\section{Basic Organizational Competitive Risks Assumptions \\ Competitors \\ Threatens}

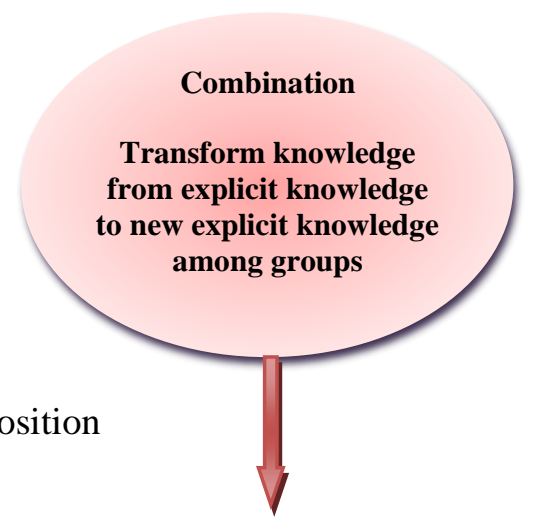

Figure 1: The Study Proposed Form

\subsection{Data Collection}

To test the proposed hypotheses in the present study, the inductive approach was adopted by studying the relationships between the main and secondary dimensions. Data related to hospitals and health units were collected and analyzed to support the study objectives and ease testing its model. 
For this purpose, a survey was designed to match the studied hospitals and the health unit's reality. The survey included two forms:

The first form was distributed to the administration of the studied hospitals and health units. This form consisted of two parts. The first part of it included general information regarding the hospital and the health unit names and the date of establishment besides general information about the individuals surveyed (the administration) in terms of (gender, age, academic achievement, and position). The second part of this form focused on the criteria of the studied topic. Twenty indicators were identified to measure this variable, Table (1).

The second form was distributed to customers dealing with the studied health units. This form aimed to obtain information on each level. Similarly, to the first form, the second form consisted of two parts. The first part included the customer's general and identifying information such as (gender, age, duration of contact with the health unit, and the sector in which the customer works). As for the second part of the client's survey, it included the criteria for the main research topic. For this purpose, twenty indicators were identified to measure this dimension.

In addition to the two forms of the survey, a checklist was distributed. The checklist contained indicators that specify the information on the growth level of the studied hospitals as a dimension of business results.

Generally, in all the surveys, a triple Likert scale was used, as each option was assigned a weight. Scores of (3, 2, and 1) were awarded for the answers (agreed, neutral, and disagreed), respectively.

Table 1: The Study Dimensions included in the Survey

\begin{tabular}{|l|l|}
\hline \multicolumn{1}{|c|}{ Main Variables } & \multicolumn{1}{c|}{ Sub-Variables } \\
\hline General Information & Information about the Organization \\
\hline & Personal information about the Administration \\
\hline Healthcare Knowledge Management & personal information about the Customer \\
\hline & Achievement \\
\hline & Fortune \\
\hline Strategic Position & knowledge Investment \\
\hline
\end{tabular}




\subsection{Test the Survey Validity and Reliability}

\subsubsection{Tests before Distributing the Survey}

In order to ensure the ability of the survey to measure the study variables, a test of the apparent validity of the statements of the survey was conducted. The opinion of a group of specialized experts in administrative sciences was surveyed. Their opinion is crucial to ensure the validity of the survey dimensions and expressions and their suitability to the study hypotheses and its objectives. The experts were surveyed regarding the ability of dimensions and expression to measure the study variables to ensure clarity and easy understanding by participants besides its accuracy from the scientific point of view. Then the experts' suggestions were discussed and the necessary amendments, deletions, and addition were made to fulfill most of the expert's suggestions.

In addition, comprehensiveness measurement was performed. Comprehensiveness measurement was tested based on asking a set of questions to referees and specialists about the comprehensiveness of the survey. In light of the questions raised and the answers that resulted from it, some phrases were added, some of them were deleted, and some of them were replaced with a more appropriate one.

\subsubsection{Tests after Distributing the Survey}

The distributed survey was highly neutral. The answers to the study participant did not interfere with or influence by the researchers. The neutrality was applied to obtain objective answers far from bias and to give the opportunity to all participants to express their true opinion. Accordingly, everyone was given sufficient time to answer the survey questions. The survey extended from $15 / 2 / 2020$ to $15 / 4 / 2020$ which ensured access to all the distributed forms.

\section{Analysis and Testing the Study Variables}

In this section, the study variables were defined. Then the correlations between the study variables were measured through statistical analysis. The used statistical methods were reported.

\subsection{Study Variables}

In the present study, the correlations between the study variables included in the main hypothesis of the research, and the sub hypotheses that emanate from it were measured. Simple correlation coefficients were tested using the statistic test $(\mathrm{t})$ to give an accurate validation of the main hypothesis. Then the sub-hypotheses were tested. A correlation relationship is analyzed between the independent variables represented in the management of healthcare knowledge (socialization, 
internalization, mixing, and embodiment) and the variables adopted in the research represented in the strategic position of the organization from (market opportunities, competitors' threats, emerging risks, and basic organizational assumptions). For this purpose, the research developed the following hypotheses:

- Main Hypothesis: there is a statistically significant relationship between the dimensions of hkm and the strategic location of the organization. the following sub hypotheses branch out from it:

- First Sub-Hypothesis: There is a statistical relationship between socialization and the strategic position of the organization.

- Second Sub-Hypothesis: There is a statistical relationship between internalization and the strategic position of the organization.

- Third Sub-Hypothesis: There is a statistical relationship between the combination and the strategic position of the organization.

\subsection{Methods of Statistical Analysis}

A group of statistical methods was used in order to reach the objectives of the present study and test its hypotheses. The analyses were performed using statistical software (SPSS). They used statistical methods were as follows:

1. Frequencies, percentages, arithmetic means, and standard deviations, as they are tools for describing research dimensions and presenting and discussing the initial results.

2. Multiple correlation coefficients to determine the strength and nature of the relationship between a set of explained dimensions and the dimension of a single respondent.

3. Multiple regression is used to measure the effect of the dimensions explained in the responsive dimension.

4. The significance of the model and the dimensions adopted in the research based on (F) and ( $t)$ test.

\section{Findings}

This section deals with the findings of the relationship between the independent variable healthcare knowledge management HKM and the dependent variable the organization's strategic position. The main results obtained from testing the three sub-hypotheses are as follows: 


\subsection{Testing the First Sub-Hypothesis:}

Table 2 indicates the correlation coefficient values between the dimension of socialization (x1) and the adopted variables.

Table 2: The Relationship between Socialization and the Strategic Position of the Organization

\begin{tabular}{|c|c|c|c|c|c|c|}
\hline Y1, Y4 & $\begin{array}{c}\text { Market } \\
\text { Opportunities }\end{array}$ & $\begin{array}{c}\text { Competitors } \\
\text { Threatens }\end{array}$ & $\begin{array}{c}\text { Emerging } \\
\text { Risks }\end{array}$ & $\begin{array}{c}\text { Basic } \\
\text { Organizational } \\
\text { Assumptions }\end{array}$ & \multicolumn{2}{|c|}{$\begin{array}{c}\text { Calculated } \\
\text { (t) Value }\end{array}$} \\
\hline $\begin{array}{c}\text { Correlation } \\
\text { coefficient } \\
(\mathrm{r})\end{array}$ & 0.165 & 0.185 & 0.09 & -0.027 & $(1 \%)$ & $(5 \%)$ \\
\hline $\begin{array}{c}\text { calculated } \\
\text { (t) value }\end{array}$ & 1 & 1.1 & 0.54 & 0 & 2.750 & 2.042 \\
\hline Trust degree & --- & --- & --- & --- & $90 \%$ & $95 \%$ \\
\hline
\end{tabular}

To verify a relationship between (x1) and each dimension of the organization's strategic position (y), it is necessary to examine the correlation relationship between (x1) and each mentioned dimension with (y), Table 2:

- The calculated (t) value for the correlation between (x1) and market opportunities (y1) is 1. It is less than its value at the level of significance (1\%), (5\%), which indicates the absence of a positive and strong correlation between (x1) and (y1). It is statistically insignificant at the aforementioned level. This means that the interest of the surveyed sample with the dimension of socialization was so low that it lacks contribution to achieve the research goal of the sample measured by market opportunities.

- The calculated ( $\mathrm{t})$ value for the correlation between (x1) and the threats of competitors ( $\mathrm{y} 2)$ is 1.1. It is less than its value at the level of significance (1\%), (5\%), which indicates the absence of a strong correlation between (x1) and (y2). It is insignificant statistically at the aforementioned level. Based on the foregoing, it is evident that the interest of the surveyed sample in the dimension of socialization unclearly contributes to achieving a strategic position.

- The calculated (t) value for the correlation between (x1) and the emerging risk (y3) is 0.54 . It is less than its value at the level of significance (1\%), (5\%), which indicates the absence of a positive and strong correlation between (x1) and (y3). It is insignificant statistically at the 
mentioned level. This means that the interest of the surveyed sample in the dimension of socialization lacks contribution to achieve high emerging risks.

- The calculated (t) value for the correlation between (x1) and basic organizational assumptions (y4) is 0 . It is less than its value at the level of significance (1\%), (5\%), which indicates the absence of a strong correlation between (x1) and (y4). It is statistically insignificant at the aforementioned level. Based on the foregoing, it is evident that the sample interest in the dimension of socialization unclearly contributes to increasing basic organizational assumptions.

From the above, it is evident that the interest of the surveyed sample in the dimension of socialization unclearly contributes to achieving a strong strategic position in it. As a result, the validity of the first sub-hypothesis of the research is not proven.

\subsection{Testing the Second Sub-Hypothesis:}

Table 3 indicates the values of the correlation coefficients between the internalization variable as an independent variable and the dependent variables, i.e., the strategic position of the organization.

Table 3: The Correlation between Internalization and the Strategic Position of the Organization

\begin{tabular}{|c|c|c|c|c|c|c|}
\hline Y1, Y4 & $\begin{array}{c}\text { Market } \\
\text { Opportunities }\end{array}$ & $\begin{array}{c}\text { Competitors } \\
\text { Threatens }\end{array}$ & $\begin{array}{c}\text { Emerging } \\
\text { Risks }\end{array}$ & $\begin{array}{c}\text { Basic } \\
\text { Organizational } \\
\text { Assumptions }\end{array}$ & \multicolumn{2}{|c|}{$\begin{array}{c}\text { Calculated } \\
\text { (t) Value }\end{array}$} \\
\hline $\begin{array}{c}\text { Correlation } \\
\text { coefficient } \\
\text { (r) }\end{array}$ & 0.005 & 0.109 & 0.003 & -0.228 & $(1 \%)$ & $(5 \%)$ \\
\hline $\begin{array}{c}\text { calculated } \\
\text { (t) value }\end{array}$ & 0.03 & 0.7 & 0.02 & 0 & 2.750 & 2.042 \\
\hline Trust degree & --- & -- & --- & --- & $90 \%$ & $95 \%$ \\
\hline
\end{tabular}

To investigate the relationship between the internalization dimension (x2) and each dimension of the institution strategic center $(\mathrm{y})$ in detail, it is necessary to examine the relationship between the internalization dimension (x2) and each dimension of the enterprise's strategic position (y), Table 3:

- The calculated (t) value for the correlation between (x2) and market opportunities (y1) is 0.03. It is less than its value at the level of significance $(1 \%),(5 \%)$, which indicates the absence of a positive and strong correlation between (x2) and (y1). It is insignificant statistically at the aforementioned level. This means that the interest of the surveyed sample in (x2) was so low that it lacks contribution to achieve the research goal for the sample measured by market 
opportunities.

- The calculated (t) value for the correlation between (x2) and the threats of competitors (y2) is 0.7. It is less than its value at the level of significance (1\%), (5\%), which indicates the absence of a strong correlation between (x2) and (y2). It is insignificant statistically at the aforementioned level. Based on the foregoing, it is evident that the interest of the surveyed sample in (x2) lacks contribution to increasing the threats of competitors.

- The calculated $(\mathrm{t})$ value for the correlation between $(\mathrm{x} 2)$ and the emerging risk $(\mathrm{y} 3)$ is 0.02 . It is less than its value at the level of significance (1\%), (5\%), which indicates the absence of a positive and strong correlation between (x2) and (y3). It is statistically insignificant at the aforementioned level. This means that the interest of the surveyed sample in (x2) lacks contribution to achieve the high emerging risks.

- The calculated (t) value for the correlation between (x2) and basic organizational assumptions (y4) is 0 . It is less than its value at the level of significance $(1 \%),(5 \%)$, which indicates the absence of a strong correlation between (x2) and (y4). It is statistically insignificant at the aforementioned level. Based on the foregoing, it is evident that the interest of the surveyed sample in (x2) lacks contribution to increasing basic organizational assumptions.

From above, it is clear that the interest of the surveyed sample in the internalization dimension unclearly contributes to achieving a strong strategic position in it. As a result, the validity of the second sub-hypothesis of the research is not proven.

\subsection{Testing the Third Sub-Hypothesis:}

Table 4 indicates the values of the correlation coefficients between the combination variable as an independent variable, and the dependent variables, i.e., the strategic position of the organization.

Table 4: The Correlation between the Combination and the Strategic Position of the Organization

\begin{tabular}{|c|c|c|c|c|c|c|}
\hline Y1, Y4 & $\begin{array}{c}\text { Market } \\
\text { Opportunities }\end{array}$ & $\begin{array}{c}\text { Competitors } \\
\text { Threatens }\end{array}$ & $\begin{array}{c}\text { Emerging } \\
\text { Risks }\end{array}$ & $\begin{array}{c}\text { Basic } \\
\text { Organizational } \\
\text { Assumptions }\end{array}$ & $\begin{array}{c}\text { Calculated } \\
\text { (t) Value }\end{array}$ \\
\hline $\begin{array}{c}\text { Correlation } \\
\text { coefficient } \\
\text { (r) }\end{array}$ & 0.286 & 0.330 & 0.256 & -0.201 & $(1 \%)$ & $(5 \%)$ \\
\hline $\begin{array}{c}\text { Calculated } \\
\text { (t) value }\end{array}$ & 1.79 & 2.1 & 1.57 & -1.2 & 2.750 & 2.042 \\
\hline Trust degree & --- & --- & --- & --- & $90 \%$ & $95 \%$ \\
\hline
\end{tabular}


To verify a relationship between the dimension of the combination (x3) and each dimension of the strategic center of the organization (y) in detail, it is necessary to examine the correlation relationship between (x3) and each stated dimension of the strategic center of the organization (y). The results of Table 4 show the following:

- $\quad$ The calculated (t) value for the correlation between (x3) and market opportunities (y1) is 1.79. It is less than its value at the level of significance (1\%), (5\%), which indicates the absence of a positive and strong correlation between $(\mathrm{x} 3)(\mathrm{y} 1)$. It is insignificant statistically at the aforementioned level. This means that the interest of the surveyed sample with (x3) was so low that it lacks contribution to achieve the research goal for the sample measured by market opportunities.

- The calculated $(\mathrm{t})$ value for the correlation between $(\mathrm{x} 3)$ and the threats of competitors (y2) is 2.1. It is less than its value at the level of significance (1\%), (5\%), which indicates the absence of a strong correlation between (x3) and (y2), and it is insignificant statistically at the aforementioned level. Based on the foregoing, it is evident that the interest of the sample covered by the research with the dimension of the combination (x3) unclearly contribute to the threats of competitors.

- The calculated $(\mathrm{t})$ value for the correlation between $(\mathrm{x} 3)$ and the emerging risk (y3) is 1.57 . It is less than its value at the level of significance $(1 \%),(5 \%)$, which indicates the absence of a positive and strong correlation between (x3) and (y3), and it statistically insignificant at the mentioned level. This means that the interest of the surveyed sample with (x3) lacks contribution to achieve the high emerging risks.

- The calculated ( $\mathrm{t}$ ) value for the correlation between (x3) and basic organizational assumptions (y4) is -1.2 . It is less than its value at the level of significance $(1 \%),(5 \%)$, which indicates the absence of a strong correlation relationship between (x3) and (y4). It is statistically insignificant at the aforementioned level. Based on the foregoing, it is evident that the interest of the surveyed sample in (x3) insignificantly contributes to increasing basic organizational assumptions.

- From above, it is evident that the interest of the surveyed sample in the dimension of the combination unclearly contributes to achieving a strong strategic position in it. As a result, the validity of the third sub-hypothesis of the research is not proven. 
From Tables 2, 3, and 4, it can be concluded that the rank of the strength of the relationship is a combination, internalization, then socialization.

\section{Conclusions}

The most important drawn conclusions can be summarized as:

- Market Opportunities are a form of strategic input for competitive intelligence and have gained a positive trend. Market Opportunities are closely related to the strategic options preferred by Iraqi hospitals and health units.

- The Iraqi hospitals and healthcare units operate in highly competitive markets, which explains the increasing need for HKM and strategic positioning.

- The great emergence of the healthcare knowledge management administration in hospitals and health units. This administration sheds light on the tacit health knowledge, i.e. socialization (x1), that receives insignificant attention in the absence of this administration, despite the fact that the tacit healthcare knowledge is a major and important resource for the organization.

- The transformation of healthcare knowledge from explicit knowledge to tacit knowledge, i.e., Internalization (x2), at the level of a group or to an individual is noticed. Also, it was high because the working individual always tries to add to his experience what he observes from written information in addition to benefiting from the experiences of others.

- The process of transforming health knowledge from explicit knowledge to other explicit knowledge, and at the group level, i.e., combination (x3), was also high. It can be gained through the access of working individuals to what is in the records, documents, and leaflets in the Iraqi organization.

In spite of the authors' effort to study most of the aspects that impact the HKM, still, there are few points to be considered in the future. Based on the present findings, the authors recommend studying the effect of job nature on the HKM. It would be helpful to study the impact of each employee in a healthcare organization on the HKM (Sabeeh et al., 2016).

However, the present work faced various limitations due to applying HKM in reality. Applying HKM suffers from doubt about its efficiency, incorrect information, absence of trust, and network failure. 


\section{REFERENCES}

Al-Ma'adidi \& Maan, Adallah, (2001). Enhancing strategic capabilities using some financial indicators: An applied study of a sample of business establishments registered in Baghdad Stock Exchange. A Ph.D. dissertation, College of Management and Economics, University of Mosul.

Almansoori, A., AlShamsi, M., Salloum, S. A., \& Shaalan, K. (2020). Critical Review of Knowledge Management in Healthcare. Recent Advances in Intelligent Systems and Smart Applications, 99-119. https://doi.org/10.1007/978-3-030-47411-9_6

Baskici, C. (2017). Transfer of heterogeneous knowledge along the dual-network of MNCs. PEOPLE: International Journal of Social Sciences, 3(2). https://doi.org/10.20319/pijss.2017.32.965981

El Morr, C., \& Subercaze, J. (2010). Knowledge management in healthcare. In Handbook of research on developments in e-health and telemedicine: Technological and social perspectives (pp. 490510). IGI Global. https://doi.org/10.4018/978-1-61520-670-4.ch023

Fahey, L. (2007). Connecting Strategy and Competitive Intelligence: Refocusing Intelligence to Produce Critical Strategy Inputs. Strategy and Leadership, 35(1). https://doi.org/10.1109/EMR.2008.4648892

Hajric, E. (2018). Knowledge management: System and practices. Eur. Manag. J.

Klimko, G. (2001, November). Knowledge management and maturity models: Building common understanding. In Proceedings of the 2nd European Conference on Knowledge Management (Vol. 2, pp. 269-278). Bled, Slovenia.

Kruger, C. N., \& Johnson, R. D. (2010). Information management as an enabler of knowledge management maturity: A South African perspective. International journal of information management, 30(1), 57-67. https://doi.org/10.1016/j.ijinfomgt.2009.06.007

Mark, P., Curtis, B., Chrissis, M. \& Webber, S. (1993). Capability maturity model, version 1.1. IEEE Software, 10(3): 7-27. https://doi.org/10.1109/52.219617

Najm, A. (2010). Managing the Intangibles: Managing the Immeasurable. Al-Yazouri Scientific Publishing and Distribution House, Amman, Jordan.

Nwokah, N. G., \& Ondukwu, F. E. (2009). Competitive intelligence and marketing effectiveness in corporate organizations in Nigeria. African Journal of Marketing Management, 1(1), 010-022. https://doi.org/10.5897/AJMM09.005 
Paulk, M. C., Curtis, B. B., Chrissis, M. B. \& Weber, C. V., (1991). The Capability Maturity Model for Software. Vol. 1, Software Engineering Institute, Carnegie Mellon University, Pittsburg, PA, U.S.A.

Sabeeh, Z. A., Syed Mustapha, S. M. F. D., \& Mohamad, R. (2016). A review of three models for knowledge management in healthcare organizations.

Sensuse, D. I., Sucahyo, Y. G., Rohajawati, S., Rizqi, H., \& Anggia, P. (2014, April). Knowledge management: Organization culture in healthcare Indonesia. In Information and Communication Technology-EurAsia Conference (pp. 108-118). Springer, Berlin, Heidelberg. https://doi.org/10.1007/978-3-642-55032-4_11

Yulita, M. T., \& Nasution, Y. (2018). Leadership Effect and Dynamic Capability on The Speed of Decision Making in Hospitals. PEOPLE: International Journal of Social Sciences, 4(3). https://doi.org/10.20319/pijss.2019.43.11811197 